\title{
A significant enhancement of catalytic performance by adjusting catalyst wettability
}

\author{
Liang Wang and Feng-Shou Xiao*
}

Heterogeneous catalysts have played a crucial role in upgrading fuels, transforming biomass [1-3], removing pollutants [4-6], harvesting solar energy [7-9], and producing fine chemicals $[10,11]$. Compared with homogeneous catalysts, the heterogeneous catalysts have obvious advantages in easy separation and regeneration from the reaction systems [12-15], but still have unsatisfactory activity and/or selectivity. These issues are reasonably assigned to the limited molecular diffusion on the heterogeneous catalysts. Therefore, it is in great demand to improve the catalytic performances of these catalysts by increasing mass transfer in the reactions, which is always a challenge in the heterogeneous catalysis.

For a general reaction from $A$ and $B$ reactants to $C$ and $\mathrm{D}$ products, the rate of a chemical reaction is sensitive to the concentration of the reactants and products, as shown in Equation (1) ( $r$ is the reaction rate, $[\mathrm{A}-\mathrm{D}]$ is the concentration of reactants $\mathrm{A}-\mathrm{D}, a-d$ is the kinetic reaction order of reactants $\mathrm{A}-\mathrm{D})$ :

$$
r=[\mathrm{A}]^{a}[\mathrm{~B}]^{b} /[\mathrm{C}]^{c}[\mathrm{D}]^{d}
$$

Therefore, it is reasonable to improve the reaction rate by increasing the concentration of reactants and reducing the concentration of products close to the active centers. Normally, a heterogeneous catalysis [16] mainly includes the adsorption of reactant, reactant transfer on the catalyst surface, reactant conversion from reactants to products, product transfer on the catalyst surface, and desorption of products, as presented in Scheme 1. In these steps, four steps are related to the molecular diffusion in the reaction.

It is well known that the molecular diffusion is strongly influenced by catalyst wettability. The recent results have demonstrated that the adjustment of catalyst wettability would lead to (i) enrichment of the reactants for accelerating the reaction, (ii) fast diffusion of the products for shifting the reaction balance, (iii) formation of new re- action intermediates, (iv) isolation of undesired molecules for hindering the side reactions, and (v) stabilization of the catalyst structure.

Enrichment of reactants for increasing catalytic activity As illustrated in Equation (1), enhancement of reactant concentration should effectively increase the reaction rate. In the beginning, it was focused on the zeolite catalysts. One typical example is the industrial TS-1 zeolite with hydrophobic framework, which is not favorable for adsorption of $\mathrm{H}_{2} \mathrm{O}_{2}$ in the oxidations of organic compounds with $\mathrm{H}_{2} \mathrm{O}_{2}$ because the $\mathrm{H}_{2} \mathrm{O}_{2}$ is polar and hydrophilic [17-20]. Obviously, the TS-1 zeolite with more hydrophilicity might be helpful to enrich the $\mathrm{H}_{2} \mathrm{O}_{2}$, leading to improvement of the catalytic activities. As expected, Wang et al. [21] synthesized hydrophilic TS-1 zeolite by employing organosilicon as precursor, followed by calcination to transform the organic groups into silanol groups. The TS-1 zeolite with more hydrophilic silanol groups exhibits much higher reaction rate $\left(4.9 \mathrm{mmol} \mathrm{L}^{-1} \mathrm{~min}^{-1}\right)$ than the conventional TS-1 $\left(0.6 \mathrm{mmol} \mathrm{L}^{-1} \mathrm{~min}^{-1}\right)$ in the oxidation of 1-hexene with $\mathrm{H}_{2} \mathrm{O}_{2}$, because the hydrophilic zeolite can effectively enrich the concentration of $\mathrm{H}_{2} \mathrm{O}_{2}$ reactant in the zeolite micropores, as confirmed by the molecule adsorption and water-droplet contact angle tests. When a chirally modified $\mathrm{Pt}$ nanocatalyst was confined within the carbon

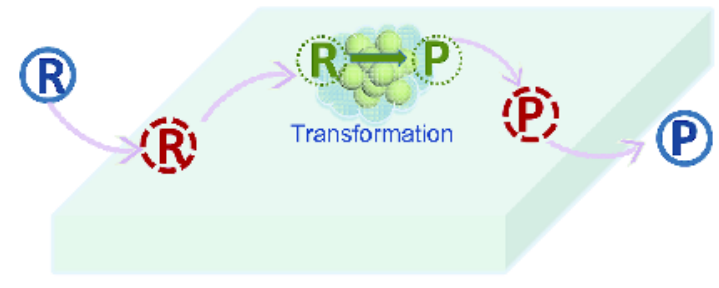

Scheme 1 A whole heterogeneous catalysis ( $\mathrm{R}=$ reactants, $\mathrm{P}=$ products). 

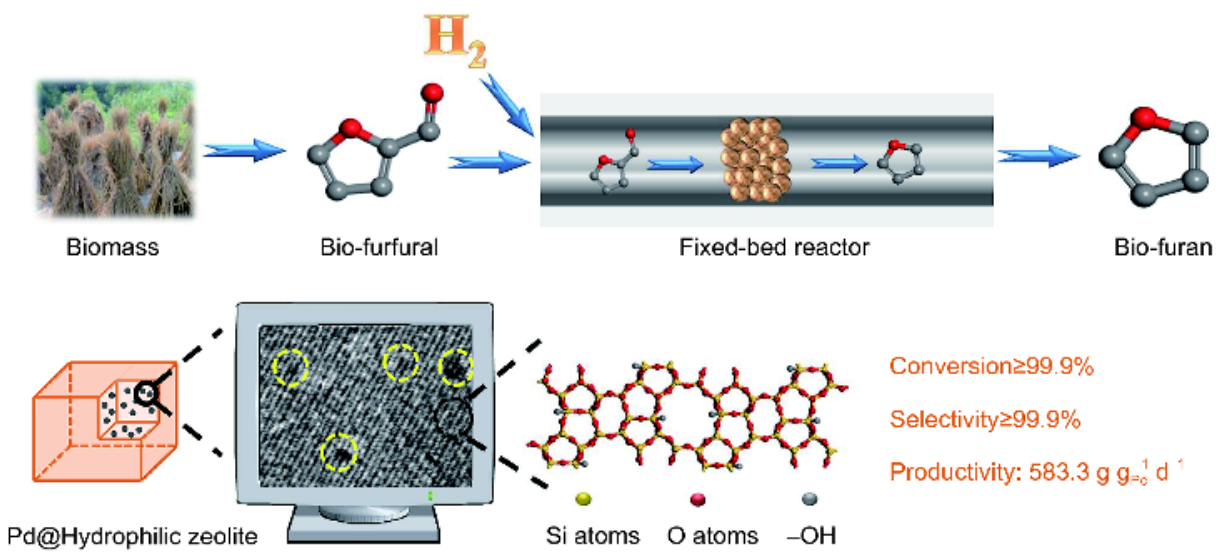

Scheme 2 Catalytic strategy for producing bio-furan over a hydrophilic zeolite fixed Pd nanoparticle catalyst. Reprinted with permission from Ref. [33]. Copyright 2018, American Chemical Society.

nanotubes, the activity (turnover frequency (TOF) of $1.0 \times 10^{5} \mathrm{~h}^{-1}$ ) and enantioselectivity (96\%) were greatly enhanced in asymmetric hydrogenation of a-ketoesters, compared with the Pt species on the external surface of carbon nanotubes (TOF of $15,000 \mathrm{~h}^{-1}$, enantioselectivity at 75\%) [15]. This phenomenon is reasonably assigned to the ultrahigh enrichment of the chiral modifier and reactants within the channels of carbon nanotubes.

Recently, a series of organic porous polymers with controllable wettability have been developed [22-26]. By functionalizing the catalytically active sites into the porous polymers, the heterogeneous catalysts with controllable wettability display excellent catalytic performances. For example, the hydrophobic porous polymer functionalized with acidic ionic liquid groups could efficiently catalyze the transesterification of tripalmitin with methanol to biofuels [27], exhibiting an activity even higher than that of the corresponding homogeneous ionic liquids. This phenomenon is strongly related to the hydrophobic nature of the catalyst with superior wettability to the tripalmitin and methanol reactants, benefiting the adsorption and enrichment of reactant within the nanopores. Furthermore, the chiral ligands [e.g., bis(diphenylphosphino)-1,1'-binaphthyl (BINAP) and $N$-(p-toluenesulfonyl)-1,2-diphenylethylenediamine (TsDPEN)] are also functionalized onto the porous polymer network, followed by coordination with $\mathrm{Rh}$ sites to achieve the heterogeneous catalysts. Interestingly, these catalysts give comparable activities and enantioselectivities to those of the corresponding homogeneous catalysts $[25,26]$.

In addition, the strategy for adjusting catalyst wettability is extended to prepare supported metal nanoparticle catalysts and metal-organic frameworks (MOFs)
[28-31]. Cao and co-workers [28] developed hydrophobic carbon supported Pd nanoparticles, showing higher activities for the dehydrogenative coupling of organosilanes with alcohols and amines than those of the existing catalysts. Jiang and co-workers [29] developed a polydimethylsiloxane coating for a $\mathrm{Pd} / \mathrm{MOF}$ composite, realizing significantly enhanced catalytic performance in nitroarene hydrogenation by enriching the molecules. Huo and co-workers [30] covered Pt loaded MOF crystals with hydrophilic graphene oxide and hydrophobic reduced graphene oxide, achieving different catalysts with selectivity in the hydrogenation of hydrophilic or hydrophobic nitroarene molecules.

\section{Fast desorption of products for increasing catalytic activity and selectivity}

Apart from the reactant enrichment, the fast desorption of products to decrease the concentration around the active centers is also favorable for increasing catalytic activity according to Equation (1). In order to adjust the product diffusion, Wang et al. $[32,33]$ developed a route for capsulation of catalytically active sites within the zeolite crystals. Because the diffusion rates of various products are quite different in the zeolite micropores, it is possible to achieve high activity and selectivity for the desirable product by adjusting zeolite wettability. For example, furfural hydrogenation has more than eight products on general supported Pd catalysts. However, Pd nanoparticles fixed with the silanol modified silicate-1 zeolite showed a sole furan product at full conversion of furfural (Scheme 2). This phenomenon is reasonably assigned to very high diffusion rate within the zeolite micropores, where the diffusion rate of furan is maximized, while the diffusion of the by-products (furfural, dihy- 
drofuran, tetrahydrofuran, and furfuryl alcohol) is strongly hindered. The fast desorption of furan leads to the selective formation of furan as a sole product. Indeed, the controllable molecular diffusion in the heterogeneous catalysis is favorable for the shift of reaction equilibrium to the products, enhancing the catalytic activities and selectivities.

\section{Formation of new intermediates}

The adjustment of catalyst wettability not only changes mass transfer of reactants/products, but also promotes the formation of new reaction intermediates. In the hydrogenation of $\mathrm{CO}_{2}$ into methanol, Peng et al. [34] found that the $\mathrm{SiC}$ quantum dots exhibit remarkably higher activity $\left(0.27 \mathrm{mmol} \mathrm{m}^{-2} \mathrm{~h}^{-1}\right)$ than commercial $\mathrm{SiC}$ $\left(0.01 \mathrm{mmol} \mathrm{m}^{-2} \mathrm{~h}^{-1}\right)$. Kinetic studies reveal that the activation energy for $\mathrm{SiC}$ quantum dots was $48.6 \mathrm{~kJ} \mathrm{~mol}^{-1}$, about half of that $\left(94.7 \mathrm{~kJ} \mathrm{~mol}^{-1}\right)$ for commercial SiC. Further studies show that the $\mathrm{SiC}$ quantum dots are hydrophilic due to rich surface hydroxyl groups. These hydroxyls are favorable for the formation of $\mathrm{HCOO}^{*}$ as a new intermediate, which effectively decreases the energy barrier in $\mathrm{CO}_{2}$ hydrogenation. These results provide unique insights into the role of catalyst wettability for the intermediate formation.

\section{Isolation of water molecules for hindering the side reactions}

In the catalytic transformations, the side-reactions usually occur to give by-products. As a typical example, the acidcatalyzed dehydration of fructose has been regarded as a general route for producing 5-hydroxymethylfurfural (HMF), an important biomass-derived platform by US Department of Energy. In this process, the HMF product could be transformed into formic acid and levulinic acid over the acid catalyst by hydration [35]. Considering that the hydration side-reaction occurred between the product and water, it is expected to hinder the side reaction (hydration) by fast removal of the water or HMF away from the acid centers. Wang et al. [35] described a strategy to switch off the hydration of HMF by controlling the wettability of solid acid catalysts. By performing the theoretical simulation, it is found that the distance between water and acid sites is sensitive to the hydration. Therefore, separation of water molecules to acidic sites in a non-reaction zone enables switch off the side reaction. On the basis of these findings, a superhydrophobic acid catalyst was developed by co-polymerization of acidic monomers with vinylbenzene, giving a hydrophobic material with water-droplet contact angle at $\sim 104^{\circ}$. The

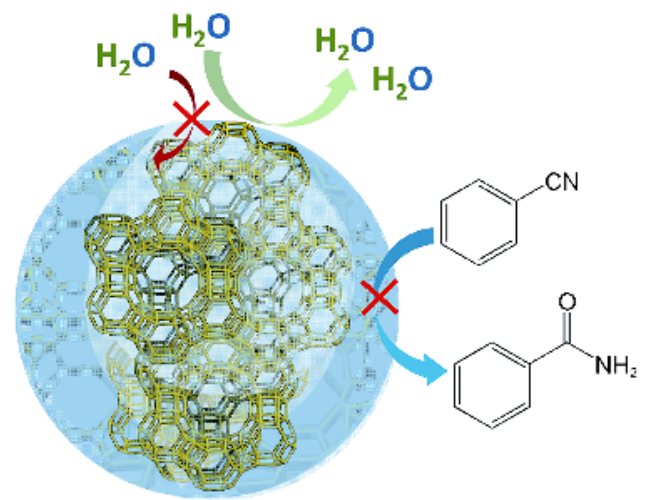

Scheme 3 Hydrophobic zeolite for hindering the water diffusion and preventing the side-reaction of hydration.

hydrophobic feature could isolate water molecules from acid centers. In the hydration of fructose, the HMF appeared as a sole product, outperforming the industrial solid acid (Amberlyst-15) and homogeneous acid catalysts (e.g., $\mathrm{H}_{2} \mathrm{SO}_{4}$ ) with low HMF selectivity $(<50 \%)$.

Recently, a persuasive example is oxidative cyanation over manganese oxide-based catalysts for producing organic nitriles [36]. Notably, manganese oxide is a good catalyst for hydration of organic nitriles into amides, giving amides as major products in the oxidative cyanation. The traditional strategy for selective production of nitriles employs the unsustainable post-treatments, such as dehydration with thionyl chloride. Considering that occurrence of this side reaction requires water as a reactant, Wang et al. [36] designed the fixation of manganese oxide nanoparticles with hydrophobic pure silica zeolite shells that could remarkably block the hydration of nitriles to amides in the oxidative cyanation, giving high selectivity for nitrile product, as shown in Scheme 3.

\section{Stabilization of heterogeneous catalysts by adjusting the wettability}

The stability is an important factor for heterogeneous catalysis. Generally, deactivation of the catalysts results from the damage of catalyst structure and/or poisoning of active sites. The solution to these issues for achieving stable catalysts is still challenging.

The aluminosilicate zeolites have been widely used as industrial catalysts, but they have relatively low stability in hot water $\left(200^{\circ} \mathrm{C}\right)$ because of the hydrolysis of $\mathrm{Si}-\mathrm{O}-\mathrm{Si}$ or $\mathrm{Si}-\mathrm{O}-\mathrm{Al}$ bonds to break the zeolite framework. Recently, Zapata et al. [37] employed the organic silane to modify the H-USY zeolite via a post-silylation method, obtaining hydrophobic H-USY zeolite. The hydro- 


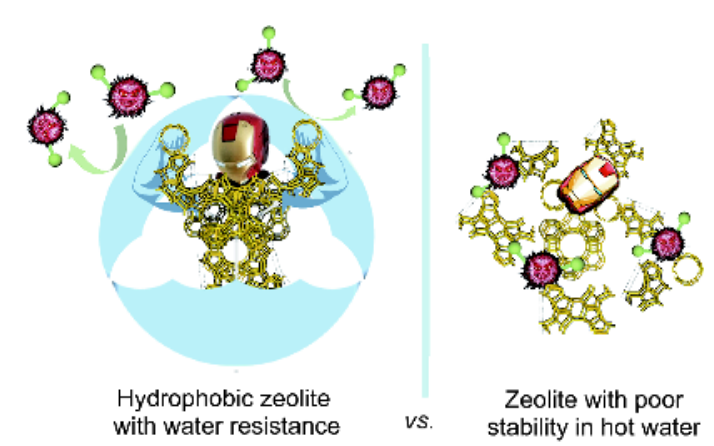

Scheme 4 Hydrophobic zeolite with water resistance at high temperature and conventional zeolite with poor stability in hot water.

phobicity of the catalyst significantly prevents the diffusion of water into the zeolite micropores for destroying the zeolite frameworks. In the catalytic tests of alkylation of $\mathrm{m}$-cresol with 2-propanol in biphasic water-oil solvent at $200^{\circ} \mathrm{C}$, the hydrophobic H-USY zeolite displays high activity and stability. In contrast, the conventional $\mathrm{H}$ USY zeolite gives unsatisfied activity and stability in the equivalent tests owing to relatively low stability in hot water (Scheme 4).

Compared with zeolites, the MOFs exhibit relatively poor stability even at room temperature in wet air, which is crucial for widely practical applications. Sun et al. [38] impart amphiphobicity onto the MOFs by chemically coating the exterior of MOF crystals with F-containing organic groups, giving extraordinary stability. In addition, hydrolytic degradation of water-sensitive organometallic catalysts is a problem in recent years because in many cases it is impossible to fully exclude water from the reaction systems. Sun et al. [24] contributed an effective approach for boosting the durability of water-sensitive ligands against hydrolysis via the construction of superhydrophobic porous polymers. For example, by introduction of porosity into the phosphite polymers, the phosphite species become water-resistant due to the formation of superhydrophobic phosphite-based catalysts.

The nickel-based catalysts are well-known in the hydrogenations, where a large amount of water in the reactions must be minimized for avoiding the formation of nickel hydroxide. To solve this problem, Lin et al. [39] developed an effective method by coating the nickel catalyst with hydrophobic carbon layer. In the hydrogenation of nitroarenes with $\mathrm{TiO}_{2}$ supported nickel nanoparticles, the catalyst with hydrophobic carbon layer exhibits remarkably enhanced recyclability compared with the catalysts without hydrophobic layer.

In conclusion, we have briefly summarized the preparation of various heterogeneous catalysts with con- trollable wettability and their catalytic performances. Clearly, the adjustment of catalyst wettability can significantly enhance the catalytic activity, product selectivity, and catalyst stability, which offers a good opportunity for the design and preparation of highly efficient heterogeneous catalysts.

Although dramatic advances have been achieved in the literatures summarized here, there are still many challenges for preparation of heterogeneous catalysts with controllable wettability. For example, it is not easy to adjust the wettability of supported metal nanoparticle catalysts due to the difficulty in controlling hydrophobicity/hydrophilicity of metal nanoparticles. Fixation of the metal nanoparticles within zeolite crystals seems a potential route to overcome this issue, because of the rich porosity and controllable wettability of zeolite crystals. Nevertheless, the methodologies for constructing the heterogeneous catalysts with controllable wettability are still developing.

\section{Received 3 April 2018; accepted 8 May 2018;}

published online 23 May 2018

1 Zhang X, Wilson K, Lee AF. Heterogeneously catalyzed hydrothermal processing of $\mathrm{C}_{5}-\mathrm{C}_{6}$ sugars. Chem Rev, 2016, 116: 1232812368

2 Dusselier M, Van Wouwe P, Dewaele A, et al. Shape-selective zeolite catalysis for bioplastics production. Science, 2015, 349: 7880

3 Mika LT, Cséfalvay E, Németh Á. Catalytic conversion of carbohydrates to initial platform chemicals: chemistry and sustainability. Chem Rev, 2018, 118: 505-613

4 Zhang R, Liu N, Lei Z, et al. Selective transformation of various nitrogen-containing exhaust gases toward $\mathrm{N}_{2}$ over zeolite catalysts. Chem Rev, 2016, 116: 3658-3721

5 Zhang C, Liu F, Zhai Y, et al. Alkali-metal-promoted $\mathrm{Pt} / \mathrm{TiO}_{2}$ opens a more efficient pathway to formaldehyde oxidation at ambient temperatures. Angew Chem Int Ed, 2012, 51: 9628-9632

6 Fan X, Zhang L, Li M, et al. a-Ferrous oxalate dihydrate: a simple coordination polymer featuring photocatalytic and photo-initiated Fenton oxidations. Sci China Mater, 2016, 59: 574-580

7 Wu F, Wang L, Chen J, et al. Direct synthesis of polysubstituted aldehydes via visible-light catalysis. Angew Chem, 2018, 130: 2196-2200

8 Zhang B, Wang S, Fan W, et al. Photoassisted oxygen reduction reaction in $\mathrm{H}_{2}-\mathrm{O}_{2}$ fuel cells. Angew Chem Int Ed, 2016, 55: 1474814751

9 Zhang G, Li G, Lan ZA, et al. Optimizing optical absorption, exciton dissociation, and charge transfer of a polymeric carbon nitride with ultrahigh solar hydrogen production activity. Angew Chem Int Ed, 2017, 56: 13445-13449

10 Jagadeesh RV, Murugesan K, Alshammari AS, et al. MOF-derived cobalt nanoparticles catalyze a general synthesis of amines. Science, 2017, 358: 326-332

11 Jagadeesh RV, Surkus AE, Junge $\mathrm{H}$, et al. Nanoscale $\mathrm{Fe}_{2} \mathrm{O}_{3}$-based catalysts for selective hydrogenation of nitroarenes to anilines. 
Science, 2013, 342: 1073-1076

12 Wang L, Meng X, Wang B, et al. Pyrrolidone-modified SBA-15 supported $\mathrm{Au}$ nanoparticles with superior catalytic properties in aerobic oxidation of alcohols. Chem Commun, 2010, 46: 50035005

13 Li B, Bai S, Wang X, et al. Hydration of epoxides on [Co ${ }^{\mathrm{III}}$ (salen)] encapsulated in silica-based nanoreactors. Angew Chem Int Ed, 2012, 51: 11517-11521

14 Yang H, Zhang L, Zhong L, et al. Enhanced cooperative activation effect in the hydrolytic kinetic resolution of epoxides on [Co (salen)] catalysts confined in nanocages. Angew Chem Int Ed, 2007, 46: 6861-6865

15 Chen Z, Guan Z, Li M, et al. Enhancement of the performance of a platinum nanocatalyst confined within carbon nanotubes for asymmetric hydrogenation. Angew Chem Int Ed, 2011, 50: 49134917

16 Wang L, Xiao FS. The importance of catalyst wettability. ChemCatChem, 2014, 6: 3048-3052

17 Blasco T, Camblor MA, Corma A, et al. Direct synthesis and characterization of hydrophobic aluminum-free $\mathrm{Ti}$-beta zeolite. J Phys Chem B, 1998, 102: 75-88

18 Bhaumik A, Kumar R. Titanium silicate molecular sieve (TS-1)/ $\mathrm{H}_{2} \mathrm{O}_{2}$ induced triphase catalysis in the oxidation of hydrophobic organic compounds with significant enhancement of activity and Para-selectivity. J Chem Soc Chem Commun, 1995, 3: 349-350

19 Serrano DP, Calleja G, Botas JA, et al. Characterization of adsorptive and hydrophobic properties of silicalite-1, ZSM-5, TS-1 and Beta zeolites by TPD techniques. Sep Purif Technol, 2007, 54: 1-9

20 Sonoda J, Kamegawa T, Kuwahara Y, et al. Hydrophobic modification of Ti-containing zeolite (TS-1) and their applications in liquid-phase selective catalytic reactions. B Chem Soc Jpn, 2010, 83: 592-594

21 Wang L, Sun J, Meng X, et al. A significant enhancement of catalytic activities in oxidation with $\mathrm{H}_{2} \mathrm{O}_{2}$ over the TS- 1 zeolite by adjusting the catalyst wettability. Chem Commun, 2014, 50: 20122014

22 Zhang Y, Wei S, Liu F, et al. Superhydrophobic nanoporous polymers as efficient adsorbents for organic compounds. Nano Today, 2009, 4: 135-142

23 Sun Q, Dai Z, Meng X, et al. Homochiral porous framework as a platform for durability enhancement of molecular catalysts. Chem Mater, 2017, 29: 5720-5726

24 Sun Q, Aguila B, Verma G, et al. Superhydrophobicity: constructing homogeneous catalysts into superhydrophobic porous frameworks to protect them from hydrolytic degradation. Chem, 2016, 1: 628-639

25 Sun Q, Dai Z, Liu X, et al. Highly efficient heterogeneous hydroformylation over Rh-metalated porous organic polymers: synergistic effect of high ligand concentration and flexible framework. J Am Chem Soc, 2015, 137: 5204-5209

26 Sun Q, Dai Z, Meng X, et al. Porous polymer catalysts with hierarchical structures. Chem Soc Rev, 2015, 44: 6018-6034

27 Liu F, Wang L, Sun Q, et al. Transesterification catalyzed by ionic liquids on superhydrophobic mesoporous polymers: heterogeneous catalysts that are faster than homogeneous catalysts. J Am Chem Soc, 2012, 134: 16948-16950

28 Lin JD, Bi QY, Tao L, et al. Wettability-driven palladium catalysis for enhanced dehydrogenative coupling of organosilanes. ACS Catal, 2017, 7: 1720-1727

29 Huang G, Yang Q, Xu Q, et al. Polydimethylsiloxane coating for a palladium/MOF composite: highly improved catalytic performance by surface hydrophobization. Angew Chem Int Ed, 2016, 55: 73797383

30 Chen X, Qian P, Zhang T, et al. Catalyst surfaces with tunable hydrophilicity and hydrophobicity: metal-organic frameworks toward controllable catalytic selectivity. Chem Commun, 2018, 54: 3936-3939

31 Sun Q, Chen M, Aguila B, et al. Enhancing the biofuel upgrade performance for Pd nanoparticles via increasing the support hydrophilicity of metal-organic frameworks. Faraday Discuss, 2017, 201: 317-326

32 Wang C, Wang L, Zhang J, et al. Product selectivity controlled by zeolite crystals in biomass hydrogenation over a palladium catalyst. J Am Chem Soc, 2016, 138: 7880-7883

33 Wang C, Liu Z, Wang L, et al. Importance of zeolite wettability for selective hydrogenation of furfural over Pd@zeolite catalysts. ACS Catal, 2018, 8: 474-481

34 Peng Y, Wang L, Luo Q, et al. Molecular-level insight into how hydroxyl groups boost catalytic activity in $\mathrm{CO}_{2}$ hydrogenation into methanol. Chem, 2018, 4: 613-625

35 Wang L, Wang H, Liu F, et al. Selective catalytic production of 5hydroxymethylfurfural from glucose by adjusting catalyst wettability. ChemSusChem, 2014, 7: 402-406

36 Wang L, Wang G, Zhang J, et al. Controllable cyanation of carbonhydrogen bonds by zeolite crystals over manganese oxide catalyst. Nat Commun, 2017, 8: 15240

37 Zapata PA, Faria J, Ruiz MP, et al. Hydrophobic zeolites for biofuel upgrading reactions at the liquid-liquid interface in water/oil emulsions. J Am Chem Soc, 2012, 134: 8570-8578

38 Sun Q, He H, Gao WY, et al. Imparting amphiphobicity on singlecrystalline porous materials. Nat Commun, 2016, 7: 13300

39 Lin $\mathrm{W}$, Cheng $\mathrm{H}$, Ming J, et al. Deactivation of $\mathrm{Ni} / \mathrm{TiO}_{2}$ catalyst in the hydrogenation of nitrobenzene in water and improvement in its stability by coating a layer of hydrophobic carbon. J Catal, 2012, 291: 149-154

Acknowledgements This work was supported by the National Key Research and Development Program of China (2017YFC0211101), the National Natural Science Foundation of China (21720102001, 91645105 and 91634201), and the Natural Science Foundation of Zhejiang Province (LR18B030002).

Author contributions Wang L and Xiao FS wrote the paper and contributed to the general discussion.

Conflict of interest The authors declare that they have no conflict of interest. 


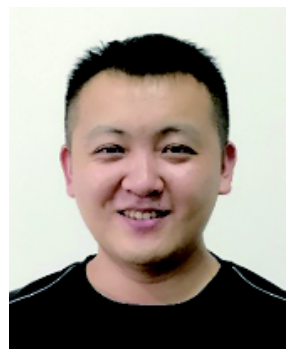

Liang Wang was born in Shandong, China in 1986. He received his BSc degree (2008) in chemistry from Jilin University, China. Since 2008, he started a continuous academic project involving master and doctor study under the guidance of Prof. Feng-Shou Xiao in the State Key Laboratory of Inorganic Synthesis and Preparative Chemistry, Jilin University and got his $\mathrm{PhD}$ degree in 2013. Then he joined the Institute of Catalysis in Zhejiang University for a postdoctoral work under the guidance of Prof. Feng-Shou Xiao. Currently he is an associate research professor of chemistry in Zhejiang University. For his research in supported metal/metal oxide catalysts, Dr. Wang was recognized with the Young Scientist Award of $16^{\text {th }}$ International Congress on Catalysis (2016) and the Rising Star Award of Catalysis in China (2017).

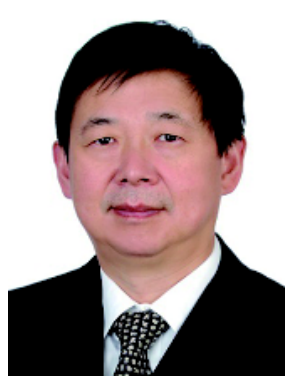

Feng-Shou Xiao received his BSc and MSc degrees from the Department of Chemistry, Jilin University, China. From there he moved to the Catalysis Research Center, Hokkaido University, Japan, where he was involved in collaborative research between China and Japan. He was a $\mathrm{PhD}$ student there for two years, and obtained his $\mathrm{PhD}$ degree at Jilin University in 1990. After postdoctoral work at the University of California at Davis, USA, he joined the faculty at Jilin University in 1994, where he is a full and distinguished professor of chemistry. He moved to Zhejiang University in 2009, and now he is a full and distinguished professor of chemistry. For his research in nanoporous materials, Prof. Xiao has been recognized with the National Outstanding Award of Young Scientists in National Science Foundation of China in 1998 and Thomson Scientific Research Fronts Award in 2008. Currently he is the secretary of Asia-Pacific Association of Catalysis Societies.

\title{
通过调控催化材料的浸润性提高其催化性能
}

\author{
王亮，肖丰收
}

摘要 固相材料的浸润性(包括亲水性、疏水性、亲油性和疏油性)已经成为设计与合成多相催化材料中必须要考虑的因素. 总结近年来 的实验结果发现, 催化材料的浸润性对分子的扩散有显著影响, 适宜的浸润性与活性中心的协同是增强催化性能的关键, 这可以通过(i) 有效富集反应物、(ii)快速扩散产物、(iii)促进形成反应中间体、(iv)避免副反应和(v)提高催化材料结构等因素来提升多相催化材料的活 性、选择性和反应寿命, 这为设计与制备高效多相催化材料提供了新机遇. 